\title{
Assessment of awareness of Andropause Induced Osteoporosis and measurement of Serum Calcium levels in Men of different age groups
}

Shameela Majeed, ${ }^{1}$ Shahid Jamal, ${ }^{1}$ Aurangzaib, ${ }^{2}$ Nabeela Naeem ${ }^{1}$

\begin{abstract}
Background: Andropause is under-emphasized in our population, and evidence is scarce on this male health problem.

Objective: To assess the andropause awareness and serum calcium level estimation in men who are at a high risk of developing osteoporosis due to age-related androgen deficiency.

Methodology: This cross-sectional study was conducted on 100 adult men from November-2018 to February-2019. The awareness collection tool was a structured questionnaire comprising of sociodemographic variables and questions which explored the awareness of osteoporosis due to andropause. Serum calcium levels were also measured in different age groups. Data collected were analyzed by Statistical Package for the Social Sciences (SPSS) version20.

Results: Overall $51 \%$ of men were aware of the term andropause while the percentage of the participants who believed that andropause may be the underlying cause of osteoporosis in advancing age was only $26.6 \%$. Serum calcium showed a negative correlation with advancing age (Pearson correlation coefficient, r-value: -0.58).

Conclusion: Though more than half of the men were aware of the knowledge of andropause they lack the awareness that osteoporosis might occur due to androgen deficiency. Moreover, decreased serum calcium levels were also observed with advancing age.
\end{abstract}

Keywords: Male menopause, Serum total calcium, Bone mineral density

Article Citation: Majeed S, Jamal S, Aurangzaib, Naeem N.Assessment of awareness of Andropause Induced Osteoporosis and measurement of Serum Calcium levels in Men of different age groups. JSZMC 2020;11(3):25-29. DOI: https://doi.org/10.47883/jszmc.v11i03.38

\section{Introduction}

Andropause- a syndrome associated with old age, is characterized by a gradual and progressive decrease of testosterone, dehydroepiandrosterone (DHEA), and growth hormones in males. ${ }^{1}$ Medically it is referred to as "ADAM-Androgen decline in Ageing Male", "LOH-Late Onset Hypogonadism" or more precisely "TDSTestosterone deficiency syndrome". ${ }^{2}$ This natural age-related phenomenon occur with similar complaints shown by the female in their menopause, that's why the term 'male menopause' was used for the first time by Heller and Meyers in 1944. ${ }^{3}$ As compared to females, in which menopause mostly starts at the age of 35-40 years, androgen deficiency relatively exhibits symptoms at a decade later (between 40-55 years). ${ }^{4}$

According to the Andropause Society, deficiency or decline in the testosterone level is the underline cause of a wide range of health effects manifested by men at the age of 40 or above. ${ }^{5}$ Testosterone is responsible for primary and secondary sex characteristics and its desired levels are also necessary to maintain the bone density. It increases the level of growth hormone and signals the bone marrow to manufacture new red blood cells. ${ }^{6}$ Testosterone levels in males drop by $1 \%$ to $2 \%$ every year after the age of 40 years. ${ }^{7,8}$ Testosterone deficiency causes psychological and sexual disturbances and its decreased levels due to andropause are also responsible for the bone loss resulting in an increased risk of secondary osteoporosis. ${ }^{9}$ Osteoporosis is the loss of calcium (bone mass) and thinning of the bones, usually caused by aging and is considered a disease of the twenty-first century. ${ }^{10}$ According to the World Health Organization (WHO-2013) report, around 70 million people worldwide were diagnosed with osteoporosis after the age of 40 , with an osteoporotic fracture occurring after every 3 seconds. ${ }^{11}$ In Asian men, 1 out of 4 fractures are osteoporotic and in 2030, this incidence will rise to 1 in $2 .{ }^{12}$ A study done in Karachi

1. Department of Pathology, Watim Medical \& Dental College, Rawat, Pakistan.

2. Department of Community Medicine, Shahida Islam Medical \& Dental College, Lodhrān, Pakistan.

Correspondence: Dr. Shameela Majeed, Department of Pathology, Watim Medical \& Dental College, Rawat, Pakistan.

Email:dr.shameela.m@gmail.com Received:16-12-2019

Revised: 05-02-2020 
in 2014 , estimated the $30.7 \%$ prevalence of osteoporosis due to andropause (24\% male and $32.6 \%$ females). ${ }^{13}$ Calcium plays a key role not only in the formation of new bone but also aid to repair the formed bone if any osteoporotic fracture occurs due to decreased bone density. ${ }^{14}$ Human body maintains its serum calcium levels within the normal limits at the expense of bone calcium. Any drop-in serum calcium overburdens the bone and enhances the osteoporotic complications by delaying the formation of new bone in men who enter the andropause phase. ${ }^{15}$

Pakistan, whose adult male population is increasing day by day, has limited facilities available to educate about the consequences of andropause. Several studies have been published regarding the awareness of menopause in women, but no detailed study has yet been targeted to address the same condition in men. Interventional and educational projects cannot be practically implemented without knowing the actual status of knowledge of andropause in men. Keeping this in mind, the present study has been designed to assess the awareness of osteoporosis due to andropause, and also to measure the calcium levels in men who are at risk of going into osteoporosis due to age-related androgen deficiency.

\section{Methodology}

This cross-sectional study was conducted at Watim Medical and Dental College, Rawat (Islamabad) for a time duration of four months (November-2018 to February-2019). A total of 100 males aged 30-70 years were selected by convenient sampling technique. This study included those individuals who were willing to participate and had at least primary education. Individuals below 30 years of age were excluded from this study.

A simple yet structured questionnaire comprising of 2 sections was used; the first section involved sociodemographic variables like age, education, marital status, smoking status, occupation, and income per year. The second section included questions that addressed the knowledge of osteoporosis due to androgen deficiency and remedial measures adopted by them. Androgen deficiency, Andropause, or male sex hormone deficiency were the terms used for labeling this disease. For calcium estimation, $5 \mathrm{ml}$ of fasting venous blood sample was collected in plain tubes under sterile conditions (not in EDTA tube as it chelate the calcium and render it unavailable for reaction with the reagent). Serum was separated from blood cells by centrifugation for 15 minutes at 2200-2500 rpm as soon as possible because prolonged contact with the clot may cause lower calcium values. Serum total calcium levels were measured by using the principle of "ISE potentiometry" on a fully automated, discrete clinical chemistry analyzer- Cobas-c501 (Roche instrument and kit).

Descriptive statistics were applied to describe the sociodemographic variables, awareness of andropause, and osteoporosis due to partial androgen deficiency in the respondents. Pearson correlation test was used to find any correlation between serum total calcium levels with the age of the individuals (Pearson correlation coefficient also known as Pearson's r-value is said to be statistically significant if the value is other than 0 i.e. if it is closer to +1 it's positively correlated, else if it is closer to - 1 the correlation goes in the opposite direction).

\section{Results}

Regarding the sociodemographic characteristics of the participants, the majority (59.2\%) of them aged between 41-70 years, with more than half (66.7\%) attained education greater than higher secondary with a yearly income of 360,000-24,00000 Pak rupees. Among the participants who knew andropause, documented the main source of their information was Mass communication media (40.7\%), Healthcare provider/doctor (36.3\%) followed by $23.1 \%$ by the relative/friend. Education level was detected significantly related to the general awareness of andropause.

The majority of the respondents $(82.4 \%)$ have the knowledge of the importance of calcium and vitamin-D in delaying the osteoporotic effects of andropause but only $18.3 \%$ were taking them in the form of supplements $(50.9 \%$ answered only balanced food is enough). Moreover, out of smokers (46\%), only $29.4 \%$ marked it as a risk factor for osteoporosis and only $15.7 \%$ believed that by quitting smoking they can delay osteoporosis due to partial androgen deficiency. (Table-I) 
Table-I: Awareness of Osteoporosis due to Andropause

\begin{tabular}{|l|c|c|}
\hline \multirow{2}{*}{ Questions } & \multicolumn{2}{|c|}{ Response } \\
\cline { 2 - 3 } & $\begin{array}{c}\text { Yes } \\
\text { (\%) }\end{array}$ & $\begin{array}{c}\text { No } \\
\text { (\%) }\end{array}$ \\
\hline $\begin{array}{l}\text { Andropause is the underlying } \\
\text { cause of Osteoporosis }\end{array}$ & 26.6 & 73.4 \\
\hline $\begin{array}{l}\text { Effects of Osteoporosis can be } \\
\text { delayed/minimized when it starts }\end{array}$ & 65.9 & 34.1 \\
\hline $\begin{array}{l}\text { Calcium and Vitamin -D can help } \\
\text { in delaying the onset of bone } \\
\text { problems due to andropause }\end{array}$ & 82.4 & 17.6 \\
\hline $\begin{array}{l}\text { Bone mineral density can be } \\
\text { maintained/increased with } \\
\text { exercise }\end{array}$ & 69.6 & 30.4 \\
\hline $\begin{array}{l}\text { Is smoking a risk factor for both } \\
\text { andropause and osteoporosis }\end{array}$ & 29.4 & 70.6 \\
\hline $\begin{array}{l}\text { Can quitting smoking delay } \\
\text { andropause and osteoporosis }\end{array}$ & 15.7 & 84.6 \\
\hline $\begin{array}{l}\text { Should men undergo bone density } \\
\text { scans after age of 40 }\end{array}$ & 69.5 & 30.5 \\
\hline $\begin{array}{l}\text { Have you ever undergone bone } \\
\text { density scans }\end{array}$ & 24.7 & 75.3 \\
\hline
\end{tabular}

When serum calcium levels were correlated with age, a negative correlation was established (Pearson correlation coefficient, r-value: -0.58) which proved a decline in serum calcium levels with advancing age. Histogram of total serum calcium levels showed that 58 subjects have serum total calcium levels in the normal range of 2.11-2.56 $\mathrm{mmol} / 1 ; 31$ subjects have calcium in the $1.89-2.11 \mathrm{mmol} / 1$ range while 11 show levels even below $1.89 \mathrm{mmol} / 1$. (Figure-I)

\section{Figure-I: Histogram of Total serum calcium} levels: Normal total serum calcium $=\mathbf{2 . 1 2 - 2 . 6 2}$ $\mathrm{mmol} / \mathrm{l}$

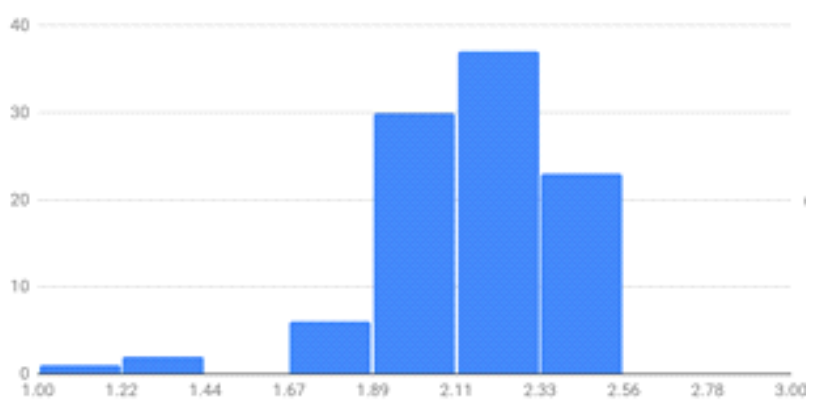

\section{Discussion}

In this study, from the overall 51\% andropause enlightened participants, $82.5 \%$ men aged between 30-40 years. It can be said that participants who had not experienced even any of the symptoms of andropause deficiency are most aware of the term "Andropause". This finding is compatible with similar studies which documented $54 \%$ and $55 \%$ awareness in the Turkish and Nigerian participants respectively in similar age groups. ${ }^{16,17}$ Even the people in the USA and Europe lack the basic and correct knowledge, though the majority had heard about andropause. ${ }^{18}$ Present study pointed out that mass media (online and offline) was the major source of their information about andropause as $40.7 \%$ of participants agreed with that option. Since the majority of the young people, $\leq 40$ years use social media more frequently than the others, this might explain both of our above findings. ${ }^{19}$ Some studies contradicted the present study findings, as the health care provider scored the greatest percentage of $63.7 \% .^{20,21}$ Like the Canadian study, most of the married young men $(72.5 \%)$ in this study were also aware about the hormonal changes in men that occur in andropause (like female menopause). ${ }^{22}$

Awareness regarding andropause might be the underlying basic cause of osteoporosis was very low $(26.6 \%)$. The majority of them $(69.9 \%)$ had the knowledge that exercise and an active lifestyle might help them to maintain or even increase their bone density. In the male, bone reaches its maximum density at 25 years (female:30 years), but studies showed that proper exercise might be helpful in increasing the bone mass for up to 10 years more. ${ }^{23}$ Participants were also well aware $(82.4 \%)$ of the calcium and vitamin-D role in andropause related bone problems. The awareness of the protective role of these supplements in osteoporosis is supported by a similar study in the past, in which a balanced diet with calcium and vitamin-D supplements showed a positive association with bone mass. ${ }^{24}$ Though approximately half of the individuals (46\%) were smokers in this study, only $29.4 \%$ thought it as a risk factor for causing early andropause with further less number (only 15.7\%) agreed to stop smoking to delay the andropause. Various studies had been conducted targeting the modifiable risk of smoking on bone mineral density and revealed that smokers have not had a greater risk of early andropause, but they had also decreased bone mineral density (BMD) and osteoporosis as compared to non-smokers (same is also true with women, relating smoking to their early menopause). ${ }^{25}$

Serum total calcium showed a negative correlation (significant $\mathrm{r}$-value $=-0.58$ ), 31 participants have 
calcium in the $1.89-2.11 \mathrm{mmol} / 1$ range while 11 (age $\geq 65$ years) showed levels even below 1.89 mmol/1. Partial androgen deficiency in osteoporosis is an important risk factor for decreased bone mass, as the body might not be able to maintain its serum level at the expense of calcium deposited in bone. ${ }^{26}$ Calcium absorption plays a major role in maintaining its levels within the normal limits and also affects bone loss with advancing age. ${ }^{27}$ Study has shown that certain changes might occur with age that alters the normal physiology of certain cytokines and growth factors and are responsible for an increased calcium and bone mass loss. ${ }^{28}$ Supported by another study, physical inactivity with advancing age with decreased calcium absorption is the underlying cause of the decline in the bone mineral density of men. ${ }^{29}$

\section{Conclusion}

Results of the study showed that more than half of the participants were aware of andropause but lack knowledge of the consequences of this age-related decline in androgen levels. Being a "silent disease" with at least one underlying cause, the bone loss in old age contributed not only to hypogonadism but also low calcium levels put them at high risk of developing bone problems in old age. This study emphasized the need for health authorities to design and implement programs that target not only andropause awareness but also educate them to maintain calcium levels. This might help them to delay the development of unavoidable osteoporosis due to testosterone deficiency.

Authors Contribution: SM: Design of Work, Acquisition, Analysis of data and drafting. SJ: Conception of work and Revising of paper. A: Acquisition \& analysis of data and revising of paper. NN: Interpretation of data, revising of paper.

All the authors gave final approval for publication and agreed to be accountable for all aspect of work.

\section{Conflict of Interest: None Sources of Funding: Self}

\section{References}

1. Balasubramanian J, Maricar KSH, Ananth DB, Vijayakumar N, Dhanalakishmi R. DHEA: the remedy for andropause. Indian J Med Health. 2012; 1:29-31.

2. Abootalebi M, Kargar M, Jahanbin I, Sharifi AA, Sharafi Z. Knowledge and attitude about andropause among general physicians in Shiraz, Iran 2014. Int J Community Based Nurs Midwifery. 2015; 4:27-35.

3. Jakiel G,Makara-Studzińska M, Ciebiera M,Słabuszewska-Jóźwiak A. "Featured paper Andropause - State of the art 2015 and review of selected aspects." Menopausal Review. 2015; 1:16.

4. Mawarao W, Mercado MR, Mitra K. Experiences of men with andropause. Adv Nurs Res. 2012; 4:4247-4241.

5. Harrisn J. Talking about my generation: a state-of-art review of health information for men in the andropause. Health Information \& Libraries Journal. 2011;28(3):161170 .

6. Gould DC, Petty R, Jacobs HS. For and against: the male menopause-does it exist? Br Med J.2000; 320:858-861.

7. Morales A, Heaton JPW, Carson CC. Andropause: a misnomer for a true clinical entity. J Urol. 2000; 163:705712 .

8. TenoverJL. Male hormone replacement therapy including "andropause." Endocrinol Metab Clin North Am. 1998; 27:969-987.

9. Sutton RAL, Dian L, Guy P. Osteoporosis in men: an under-recognized and undertreated problem. BCMJ. 2011; 53:535-540.

10. Rochira V, Balestrieri A, Madeo B, Zirilli L, Granata ARM, Carani C. Osteoporosis and male age-related hypogonadism: role of sex steroids on bone (patho)physiology. Eur J Endocrinol. 2006;154(2):175-85.

11. Piirtola M, Vahlberg T, Löppönen M, Räihä I, Isoaho R, Kivelä SL. Fractures as predictors of excess mortality in the aged- a population-based study with a 12-year followup. Eur J Epidemiol 2008; 23:747-755.

12. Kanis JA, Johnell O, De Laet C, Jonsson B, Oden A, Ogelsby AK. International variations in hip fracture probabilities: implications for risk assessment. J Bone Miner Res. 2002; 17:1237-1244.

13. Shazia Haris, Firdous Jahan, Asma Afreen, Hajra Ahmed, Zaheer Ahmed. To determine the risk factors and prevalence of osteoporosis among the adult Pakistani population residing in Karachi using quantitative ultrasound technique. J Community Med Health Educ. 2014;4(4):299.

14. Yang YJ, Kim J. Factors in relation to bone mineral density in Korean middle-aged and older men: 2008-2010 Korea National Health and Nutrition Examination Survey. Ann Nutr Metab. 2014; 64:50-59.

15. Avenell A, Mak JC, O'Connell D. Vitamin D, and vitamin $\mathrm{D}$ analogues for preventing fractures in post-menopausal women and older men. Cochrane Database Syst Rev. 2014;4:CD000227.

16. Akkuzu G, Dogan N, Karahan A. What do individuals aged 40-64 think about midlife events and their experiences: menopause and andropause. Global J Adv Pure Appl Sci. 2014; 4:283-290.

17. Adebajo S, Odeyemi K, Oyediran M, Anorlu R, Wright L. Knowledge and experiences of andropause among men in Lagos, Nigeria. West Afr J Med. 2006; 26:106-112. 
18. Anderson JK, Faulkner S, Cranor C, Briley J, Gevirtz F, Roberts S. Andropause knowledge and perceptions among the general public and health care professionals. J Gerontol Ser a Biol Sci Med Sci. 2002;57:M793.

19. Pommerville PJ, Zakus P. Andropause: knowledge and awareness among primary care physicians in Victoria, BC, Canada. Aging Male. 2006; 9:215-220.

20. Yuk Yee Yan.Awareness and Knowledge of Andropause Among Chinese Males in Hong Kong. American Journal of Men's Health. 2010; 4(3):231-236.

21. FatusiAO, Ijaduola KT, OjofeitimiEO, OdumaboAO, AdewuyiAA, Akinyemi A. The influence of sociodemographic factors on awareness and attitude towards andropause among health professionals in Ile-Ife, Nigeria. The Aging Male. 2004; 7:269-279.

22. AndersonJK, Faulkner S, CranorC, Briley, J, Gevirtz F, Roberts S. Andropause: Knowledge and perceptions among the general public and health care professionals. Journal of Gerontology. 2002; 57(A):793-796.

23. Ipsos-Reid/Organon Canada Ltd. (2002). Awareness and attitude towards andropause among Canadians. Retrieved November 10, 2008, from http://www.ipsosna.com/news/pressrelease $. c f m ? \mathrm{id}=1425$
24. Frost ML, Blake GM, Fogelman. Can the WHO criteria for diagnosing osteoporosis be applied to calcaneal quantitative ultrasound? Osteoporos Int. 2000; 11:321330 .

25. Iki M. Osteoporosis and smoking. Clin Calcium. 2005; 15:156-158.

26. Agnusdei D, Civitelli R, Camporeale A, Parisi G, Gennari L, Nardi P, et al. Age-Related Decline of Bone Mass and Intestinal Calcium Absorption in Normal Males. Calcif Tissue Int. 1998;63(3):197-201.

27. Heaney R, Gallagher J, Johnston C, Neer R, Parfitt A, Whedon G. Calcium nutrition and bone health in the elderly. Am J Clin Nutrit. 1982;36(5):986-1013.

28. Rauner M, Sipos W, Pietschmann P. Age-dependent Wnt gene expression in bone and during osteoblast differentiation. Age (Dordr). 2008; 30:273-282.

29. Scopacasa F, Wishart JM, Horowitz M, Morris HA, Need AG. The relation between calcium absorption and serum calcitriol in normal men: evidence for age-related intestinal resistance to calcitriol. Eur J Clin Nutr. 2004;58(2):264-9. 